\title{
SOLUBILIDADE DAS SUBSTÂNCIAS ORGÂNICAS
}

\author{
Cláudia Rocha Martins*, Wilson Araújo Lopes e Jailson Bittencourt de Andrade \\ Instituto de Química, Universidade Federal da Bahia, Campus Universitário de Ondina, 40170-115 Salvador - BA, Brasil
}

Recebido em 5/12/12; aceito em 13/5/13; publicado na web em 1/7/13

\begin{abstract}
ORGANIC COMPOUND SOLUBILITY. The solubility of organic compounds is a topic of great importance in chemistry and of interest in several areas, such as materials, drugs and the environment. In this paper, the solubility of these species is discussed in terms of their properties, such as the predominant type of chemical bond, molecular structure, polarity and types of intermolecular interactions. Examples of biological processes fundamental for sustainability of life and related with the solubility of chemical species are presented and discussed.
\end{abstract}

Keywords: solubility; organic species; polarity.

\section{INTRODUÇÃO}

A solubilidade é um dos temas mais relevantes da área da química, tanto pela sua importância intrínseca quanto pela variedade de fenômenos e propriedades químicas envolvidas no seu entendimento. Entretanto, os livros texto de Química geralmente abordam o tema de forma superficial ou incompleta, especialmente a solubilidade de compostos orgânicos. Em artigos anteriores ${ }^{1,2}$ são feitas considerações sobre os princípios relacionados com o processo de solubilização de compostos em geral, sendo feita uma discussão detalhada da solubilidade de alguns compostos inorgânicos. $\mathrm{O}$ texto a seguir discute as principais características das ligações e estruturas moleculares em diversas funções orgânicas que têm influência direta no processo de dissolução. Dados quantitativos sobre a solubilidade de compostos orgânicos podem ser encontrados em handbooks ${ }^{3,4}$ e sites de referência., ${ }^{5,6}$

O processo de solubilização de uma substância química resulta da interação entre a espécie que se deseja solubilizar (soluto) e a substância que a dissolve (solvente), e pode ser definida como a quantidade de soluto que dissolve em uma determinada quantidade de solvente, em condições de equilíbrio. Solubilidade é, portanto, um termo quantitativo. É uma propriedade física (molecular) importante que desempenha um papel fundamental no comportamento das substâncias químicas, especialmente dos compostos orgânicos. A solubilidade é de interesse em diversas áreas, por exemplo: materiais, farmacêutica e ambiental. Em particular, na concepção de fármacos, é essencial considerar a solubilidade aquosa, a qual influencia fortemente as propriedades farmacocinéticas, tais como absorção, distribuição, metabolismo e excreção. Além disso, o conhecimento da solubilidade é necessário para a previsão do destino ambiental de contaminantes e poluentes, processos de adsorção no solo e fatores de bioconcentração de agrotóxicos. ${ }^{7}$

A solubilidade de uma substância orgânica está diretamente relacionada com a estrutura molecular, especialmente com a polaridade das ligações e da espécie química como um todo (momento de dipolo). Geralmente, os compostos apolares ou fracamente polares são solúveis em solventes apolares ou de baixa polaridade, enquanto que compostos de alta polaridade são solúveis em solventes também polares, o que está de acordo com a regra empírica de grande utilidade: "polar dissolve polar, apolar dissolve apolar" ou "o semelhante dissolve o semelhante". A solubilidade depende, portanto, das forças de atração intermoleculares que foram documentadas pela primeira vez por Van der Waals, prêmio Nobel de Física de 1910.

\footnotetext{
*e-mail: claudia@ufba.br
}

Na realidade, é bem conhecido que a dissolução de um sólido ou de um líquido em outro líquido é um processo que requer energia necessária para vencer as atrações existentes entre as moléculas que constituem o soluto, bem como vencer as forças existentes entre as próprias moléculas do solvente. Ou seja, as forças de atração entre as moléculas do soluto e do solvente devem ser intensas o suficiente para compensar o rompimento das forças de atração entre as moléculas do soluto e entre as moléculas do solvente. Assim, o processo de dissolução de qualquer espécie é explicado de maneira adequada através da análise da energia que surge do estabelecimento de novas interações entre soluto e solvente, além dos fatores relacionados à variação de entropia $(\Delta S)$. Como o fator entropia favorece a formação das soluções, estas serão formadas se a variação da entalpia que acompanha o processo for negativa, zero ou fracamente positiva. No entanto, se a variação de entalpia for muito positiva, a variação da entropia não será suficiente para resultar uma variação de energia livre menor que zero, sendo o processo de dissolução não espontâneo. ${ }^{8}$

Diversos compostos orgânicos como o etano, $\mathrm{C}_{2} \mathrm{H}_{6}$, ou o tetracloreto de carbono, $\mathrm{CCl}_{4}$, apresentam-se comumente como espécies insolúveis em água e outros solventes polares, uma vez que são espécies apolares. As moléculas de água, fortemente polares, estão unidas umas às outras por fortes interações dipolo-dipolo, e as novas forças atrativas que poderiam se estabelecer entre as moléculas de água e as moléculas de etano ou de tetracloreto de carbono são fracas, não compensando energeticamente o processo de dissolução. Por outro lado, o etanol, $\mathrm{C}_{2} \mathrm{H}_{5} \mathrm{OH}$, um composto polar, é muito solúvel em água, uma vez que as interações dipolo-dipolo que se estabelecem entre as moléculas de água e as de etanol (ligações de hidrogênio) são da mesma ordem de grandeza das atrações do mesmo tipo existentes entre as moléculas do etanol, bem como entre as moléculas de água.

Em alguns casos, a solubilidade de compostos orgânicos pode estar relacionada com a ocorrência de uma reação química. Assim, essa propriedade pode ser dividida em duas categorias: a solubilidade em que uma reação química é a força determinante (por exemplo, na reação ácido-base) e a solubilidade na qual estão envolvidas somente as forças intermoleculares. $\mathrm{O}$ estudo semiquantitativo da solubilidade de uma substância em determinados solventes (água, éter etílico, solução diluída de hidróxido de sódio, ácido clorídrico diluído, solução de bicarbonato de sódio, ácido fosfórico concentrado e ácido sulfúrico concentrado), fornece valiosa informação sobre a presença ou ausência de determinados grupamentos funcionais ou classes de compostos orgânicos. ${ }^{9,10}$ 
Contudo, a solubilidade é uma propriedade do sistema soluto/ solvente que admite graus e é muito dependente da temperatura. Assim, para se utilizar o ensaio de solubilidade como um elemento de corte para obter-se informações sobre grupamentos funcionais, é necessário observar um valor (padrão) acima do qual a substância é considerada solúvel e, abaixo do qual, é considerada insolúvel (valor de corte). Para fins de classificação em esquemas de Análise Orgânica Sistemática, esse valor foi definido como sendo 3\% pv (três partes em peso do substrato por cem partes em volume de solvente). Os ensaios de solubilidade são extremamente úteis para se verificar a polaridade relativa de substâncias orgânicas, identificar a classe funcional e, também, para determinar os solventes (ou mistura de solventes) apropriados nas recristalizações, reações químicas, análises espectrais e análises cromatográficas., ${ }^{911,12}$

\section{CARACTERÍSTICAS GERAIS DAS MOLÉCULAS ORGÂNICAS}

As estruturas tridimensionais das moléculas orgânicas desempenham papel fundamental na determinação de suas propriedades químicas e físicas. Tendo o carbono quatro elétrons de valência ([He]2s $2 \mathrm{~s}^{2}$ ), ele forma quatro ligações em seus compostos, podendo ser ligações simples, onde os pares de elétrons são dispostos em um arranjo tetraédrico segundo o modelo da repulsão do par de elétrons no nível de valência (RPENV). ${ }^{13}$ De acordo com o modelo da hibridização, os orbitais $2 s$ e $2 p$ formam quatro orbitais híbridos do tipo $s p^{3}$, com ângulo de $109,5^{\circ}$ e geometria tetraédrica. Se ocorrer uma ligação dupla, o arranjo espacial em torno do átomo do carbono será trigonal plano (hibridização $s p^{2}$ ), com ângulo de aproximadamente $120^{\circ}$, e no caso de ocorrer uma tripla ou duas ligações duplas, o arranjo será linear (hibridização $s p$ ), com ângulo de $180^{\circ}$. Modelos moleculares com as três geometrias comuns ao redor do átomo de carbono podem ser vistos na Figura 1.
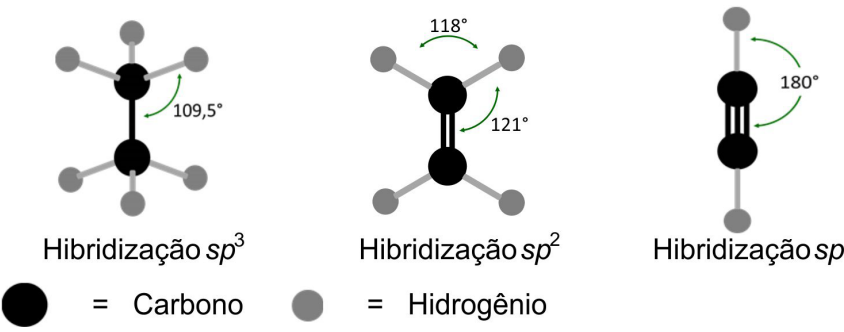

Figura 1. Modelos de hibridização do átomo de carbono e geometrias espaciais

O carbono apresenta uma propriedade excepcional de ligar-se a outros átomos de carbono, através de ligações fortes (simples, duplas ou triplas), formando cadeias ou anéis de átomos de carbono, originando uma grande variedade de moléculas. Sabe-se que o número de compostos orgânicos conhecidos é milhares de vezes o número de compostos inorgânicos. O carbono forma também ligações fortes com outros elementos químicos, especialmente com $\mathrm{H}, \mathrm{O}, \mathrm{N}$ e halogênios. As ligações $\mathrm{C}-\mathrm{C}$ formam a espinha dorsal da molécula, enquanto que as ligações $\mathrm{C}-\mathrm{H}$, presentes em quase todas as moléculas, se localizam na superfície, uma vez que o hidrogênio é capaz de formar apenas uma ligação covalente. Assim, as moléculas orgânicas apresentam tanto ligações covalentes apolares como ligações covalentes polares, que resultam do compartilhamento desigual de elétrons, devido à diferença de eletronegatividade entre os átomos ligantes.

As ligações $\mathrm{C}-\mathrm{H}$, bastante comuns nessas moléculas, são relativamente apolares, uma vez que carbono e hidrogênio apresentam valores muito próximos para eletronegatividade. Na escala de Pauling os valores de eletronegatividade são: carbono $(\mathrm{EN}=2,55)$; hidrogênio $(\mathrm{EN}=2,20)$; e cloro $(\mathrm{EN}=3,16) .{ }^{13}$ Assim, as ligações $\mathrm{C}-\mathrm{Cl}$ são polares, já que o cloro, sendo bem mais eletronegativo, atrai mais fortemente os elétrons. Dependendo da soma vetorial dos momentos de dipolo das ligações individuais, uma determinada molécula poderá ser polar ou apolar. Para determinadas geometrias, o momento de dipolo resultante será nulo e a molécula será apolar.

Na Tabela 1 podem ser vistos os valores de momentos de dipolo ( $\mu$ ) de alguns compostos orgânicos. ${ }^{14}$ Para efeito de comparação, água e amônia, substâncias inorgânicas polares, bem como cloreto de sódio (com caráter de ligação predominantemente iônico), foram inseridos na tabela.

Tabela 1. Momentos de dipolo $(\mu)$ de alguns compostos

\begin{tabular}{cccc}
\hline Substância & $\mu(\mathrm{D})$ & Substância & $\mu(\mathrm{D})$ \\
\hline $\mathrm{NaCl}$ & 9,0 & $\mathrm{NH}_{3}$ & 1,47 \\
$\mathrm{CH}_{3} \mathrm{Cl}$ & 1,87 & $\mathrm{CH}_{4}$ & 0 \\
$\mathrm{H}_{2} \mathrm{O}$ & 1,85 & $\mathrm{CCl}_{4}$ & 0 \\
$\mathrm{CH}_{3} \mathrm{OH}$ & 1,70 & $\mathrm{CH}_{3} \mathrm{CH}_{3}$ & 0 \\
$\mathrm{CH}_{2}=\mathrm{N}^{+}=\mathrm{N}^{-}$ & 1,50 & $\mathrm{C}_{6} \mathrm{H}_{6}$ & 0 \\
\hline
\end{tabular}

Como pode ser observado, substâncias como o clorometano $\left(\mathrm{CH}_{3} \mathrm{Cl}\right)$ e o metanol $\left(\mathrm{CH}_{3} \mathrm{OH}\right)$ possuem valores de momento de dipolo próximos ao da água, enquanto espécies como metano $\left(\mathrm{CH}_{4}\right)$, etano $\left(\mathrm{C}_{2} \mathrm{H}_{6}\right)$, tetracloreto de carbono $\left(\mathrm{CCl}_{4}\right)$ ou benzeno $\left(\mathrm{C}_{6} \mathrm{H}_{6}\right)$ exibem valores iguais a zero. Em razão da simetria das últimas, as polaridades individuais das ligações se cancelam, resultando em moléculas apolares, com momento de dipolo igual a zero.

Além dos haloalcanos e dos álcoois, espécies tais como éteres, aminas, tióis e sulfetos têm também átomo de carbono ligado a átomo mais eletronegativo: oxigênio, nitrogênio ou enxofre, o que confere polaridade às ligações. Os alcoóis possuem átomo de carbono ligado a um oxigênio do grupo hidroxila (-OH); os éteres, dois átomos de carbono ligados ao mesmo átomo de oxigênio; as aminas, um, dois ou três átomos de carbono ligados a um átomo de nitrogênio; os tióis, um átomo de carbono ligado a um grupo S-H; e os sulfetos, dois átomos de carbono ligados a um mesmo átomo de enxofre. As ligações são polares, resultando em cargas parciais positivas sobre os átomos de carbono $\left(\delta^{+}\right)$e cargas parciais negativas $\left(\delta^{-}\right)$sobre o átomo mais eletronegativo (Figura 2).

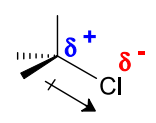

Haleto de alquila

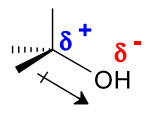

Álcool

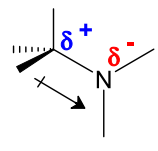

Amina

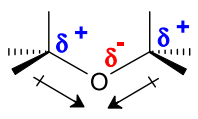

Éter
Figura 2. Ligações covalentes polares e cargas parciais

Outro tipo de ligação presente em algumas das funções mais importantes da química orgânica é a ligação dupla carbono-oxigênio, $\mathrm{C}=\mathrm{O}$ (grupo carbonila). $\mathrm{O}$ átomo de carbono do grupo carbonila exibe uma carga parcial positiva $\left(\delta^{+}\right)$e o átomo de oxigênio uma carga parcial negativa $(\delta)$. Na Figura 3 estão representadas as estruturas de algumas funções caboniladas: aldeído, cetona, ácido carboxílico e éster.

Em todos os casos, a polaridade da molécula, que é medida pelo seu momento de dipolo $(\mu)$, vai depender da soma vetorial dos momentos relacionados com as ligações polares individuais, estando, portanto, relacionada também com a disposição espacial dos átomos e com a presença de elétrons não ligantes. 
<smiles>CC(C)[C+]([O-])[O-]</smiles>

Aldeído

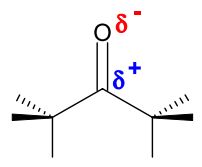

Cetona<smiles>C=C(C)C(=[O+])O</smiles>

Ácido carboxílico

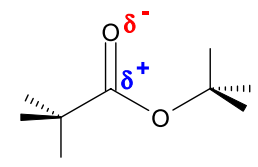

Éster
Figura 3. Grupo carbonila e funções orgânicas

\section{DISCUTINDO A SOLUBILIDADE DE SUBSTÂNCIAS ORGÂNICAS}

Soluções de solutos apolares em solventes apolares representam o processo mais simples em termos de dissolução. As forças envolvidas nas interações soluto-soluto, solvente-solvente e soluto-solvente são todas interações relativamente fracas (forças de dispersão de London), levando a mistura à formação de uma única fase. Tais soluções são chamadas soluções ideais, sendo a entalpia da solução $\Delta H=0$, e à temperatura constante a variação da energia livre será função do termo relativo à variação de entropia. ${ }^{8}$

$$
\begin{gathered}
\Delta G=\Delta H-T \Delta S \\
\Delta G=-T \Delta S(\Delta H=0)
\end{gathered}
$$

Equação 1 Equação 2

A explicação para a insolubilidade de espécies apolares em solventes polares como a água pode ser menos aparente, em função das fracas forças existentes geralmente entre as moléculas do soluto. No entanto, as interações entre moléculas do soluto e do solvente também serão fracas, não resultando energia suficiente para separar as próprias moléculas do solvente, ou seja, as moléculas do solvente apresentarão maior tendência a permanecer associadas, e o processo de solubilização não ocorre.

\section{Hidrocarbonetos}

Devido ao grande número de compostos orgânicos constituídos através da presença de ligações C-H (fracamente polares) e à simetria dos arranjos formados em torno dos átomos de carbono, estes formam um grande número de espécies, cujos momentos de dipolo resultantes são iguais a zero ou próximos de zero. Nesse grupo estão incluidos os hidrocarbonetos saturados (somente ligações C-C simples) de cadeia aberta, como os alcanos, de fórmula geral $\mathrm{C}_{\mathrm{n}} \mathrm{H}_{2 \mathrm{n}+2}$, ou os cicloalcanos, que apresentam anéis de carbono, de fórmula geral $\mathrm{C}_{\mathrm{n}} \mathrm{H}_{2 \mathrm{n}}$ (para um anel), $\mathrm{C}_{\mathrm{n}} \mathrm{H}_{2 \mathrm{n}-2}$ (para sistemas cíclicos de dois anéis) e assim por diante. As forças de dispersão de London que mantém as moléculas unidas aumentam com o crescimento do tamanho da molécula, o que leva, geralmente a um decréscimo na solubilidade. Por serem apolares, os alcanos e cicloalcanos são pouco solúveis em solventes polares como a água, sendo solúveis em solventes apolares ou de baixa polaridade como o éter. Na Tabela 2 estão apresentadas as solubilidades de alguns alcanos de cadeia aberta nos solventes água, etanol e éter. ${ }^{4}$
Os alcanos e cicloalcanos, sendo compostos não polares, são usados como solventes para dissolução de outras substâncias não polares, como matéria-prima na indústria para a síntese de outros compostos orgânicos e, também, como combustíveis. Esses hidrocarbonetos são encontrados no petróleo e no gás natural, sendo o último constituído principalmente de metano, $\mathrm{CH}_{4}$.

Os hidrocarbonetos insaturados, cujas moléculas possuem ligações múltiplas, como alcenos $(\mathrm{C}=\mathrm{C})$ e alcinos $(\mathrm{C} \equiv \mathrm{C})$, também são compostos não polares ou levemente polares, sendo portanto pouco solúveis em solventes polares como a água. Esse mesmo princípio se aplica a outra classe de hidrocarbonetos chamados hidrocarbonetos aromáticos, constituídos por estruturas cíclicas insaturadas, sendo o mais simples desses o benzeno, $\mathrm{C}_{6} \mathrm{H}_{6}$ (Figura 4).<smiles>c1ccccc1</smiles><smiles>c1ccccc1</smiles>
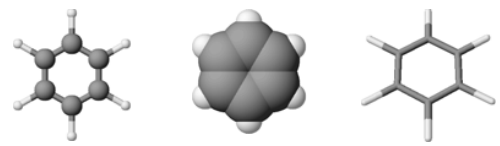

Figura 4. Diferentes representações da estrutura do benzeno

Por outro lado, estudos recentes comprovaram experimentalmente a formação de ligação entre a nuvem $\pi$ do benzeno (e de outros aromáticos) e o hidrogênio da molécula de água, evidenciando assim a formação de uma ligação de hidrogênio do tipo $\pi \cdot{ }^{15} \mathrm{~A}$ conversão de uma ligação de hidrogênio água-água (Figura 5a) em uma ligação de hidrogênio água-benzeno (nuvem $\pi$ ) (Figura 5 b) é favorecida pela entropia $(\Delta S>0)$, mas desfavorecida pela entalpia $(\Delta H>0)$. Apesar de incomum, este tipo de ligação pode ter relevância em processos biológicos. ${ }^{15}$ É importante ressaltar que a interação eletrons $\pi$ - hidrogênio não afeta a solubilidade do benzeno em água $(0,07 \mathrm{~g} / 100 \mathrm{~g}$ de $\mathrm{H}_{2} \mathrm{O}$ a $\left.23{ }^{\circ} \mathrm{C}\right),{ }^{4}$ portanto, o seu comportamento é o apresentado, em geral, pelos hidrocarbonetos: pouco solúveis em água e solúveis em solventes apolares.

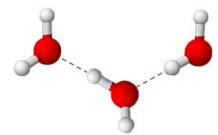

a) Ligação de hidrogênio água - água

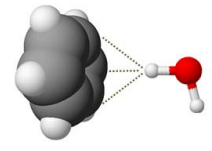

b) Ligação de hidrogênio água - benzeno
Figura 5. Representação da ligação de hidrogênio

\section{Álcoois e fenóis}

Os álcoois, compostos com um grupo funcional -OH ligado a átomo de carbono saturado, apresentam-se solúveis em solventes polares, devido à associação decorrente das ligações de hidrogênio. Assim, enquanto os hidrocarbonetos tais como metano, etano e propano são pouco solúveis em água, os álcoois de cadeias menores (até 3 átomos de carbono) metanol, etanol e propanol são infinitamente solúveis em água (totalmente miscíveis), resultado da forte ligação de hidrogênio entre água e álcool (Figuras 6 e 7).

\begin{tabular}{|c|c|c|c|c|}
\hline \multicolumn{2}{|r|}{ Substância } & \multicolumn{3}{|c|}{ Solubilidade (g / 100 g) } \\
\hline Nome & Fórmula condensada & Água & Álcool & Éter \\
\hline Hexano & $\mathrm{CH}_{3} \mathrm{CH}_{2} \mathrm{CH}_{2} \mathrm{CH}_{2} \mathrm{CH}_{2} \mathrm{CH}_{3}$ & $0,014\left(15^{\circ} \mathrm{C}\right)$ & $50\left(33^{\circ} \mathrm{C}\right)$ & Infinito* \\
\hline Heptano & $\mathrm{CH}_{3} \mathrm{CH}_{2} \mathrm{CH}_{2} \mathrm{CH}_{2} \mathrm{CH}_{2} \mathrm{CH}_{2} \mathrm{CH}_{3}$ & $0,005\left(15^{\circ} \mathrm{C}\right)$ & pouco solúvel & Infinito \\
\hline Octano & $\mathrm{CH}_{3} \mathrm{CH}_{2} \mathrm{CH}_{2} \mathrm{CH}_{2} \mathrm{CH}_{2} \mathrm{CH}_{2} \mathrm{CH}_{2} \mathrm{CH}_{3}$ & $0,002\left(16^{\circ} \mathrm{C}\right)$ & pouco solúvel & Solúvel \\
\hline Nonano & $\mathrm{CH}_{3} \mathrm{CH}_{2} \mathrm{CH}_{2} \mathrm{CH}_{2} \mathrm{CH}_{2} \mathrm{CH}_{2} \mathrm{CH}_{2} \mathrm{CH}_{2} \mathrm{CH}_{3}$ & Insolúvel & pouco solúvel & Solúvel \\
\hline
\end{tabular}

Tabela 2. Solubilidade de alguns alcanos ${ }^{4}$

*Infinito indica que a substância é completamente miscível no solvente. 


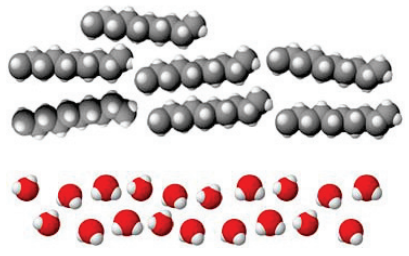

Hidrocarboneto e água

(não se misturam)

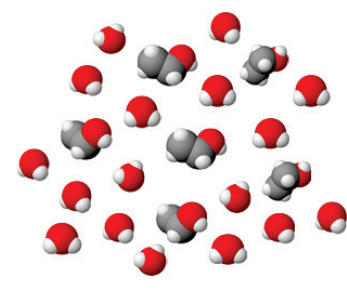

Etanol e água

(dissolução completa)

Figura 6. Representação do processo de solubilidade em água<smiles>COCO</smiles>

Metanol-água<smiles>CCOC(O)O</smiles>

Etanol-água

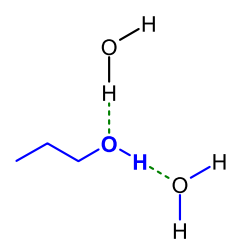

Propanol-água

Figura 7. Representação da ligação de hidrogênio entre álcoois e água

Na Tabela 3 podem ser vistos valores de solubilidade para uma série de álcoois, em água e em hexano.

Tabela 3. Solubilidade de alguns álcoois em água e hexano ${ }^{13,16}$

\begin{tabular}{cccc}
\hline & Substância & \multicolumn{2}{c}{$\begin{array}{c}\text { Solubilidade } \\
(\mathrm{g} / 100 \mathrm{~g} \text { de solvente })\end{array}$} \\
\hline Nome & Fórmula condensada & Água* & Hexano \\
\hline Metanol & $\mathrm{CH}_{3} \mathrm{OH}$ & Infinito & 3,8 \\
Etanol & $\mathrm{CH}_{3} \mathrm{CH}_{2} \mathrm{OH}$ & Infinito & Infinito \\
Propanol & $\mathrm{CH}_{3} \mathrm{CH}_{2} \mathrm{CH}_{2} \mathrm{OH}$ & Infinito & Infinito \\
$n$-Butanol & $\mathrm{CH}_{3} \mathrm{CH}_{2} \mathrm{CH}_{2} \mathrm{CH}_{2} \mathrm{OH}$ & 7,9 & Infinito \\
s-Butanol & $\mathrm{CH}_{3} \mathrm{CH}_{2} \mathrm{OH}_{2} \mathrm{CH}_{2} \mathrm{CH}_{3}$ & 12,5 & Infinito \\
-Butanol & $\left(\mathrm{CH}_{3}\right)_{3} \mathrm{COH}_{2}$ & Infinito & Infinito \\
$n$-Pentanol & $\mathrm{CH}_{3} \mathrm{CH}_{2} \mathrm{CH}_{2} \mathrm{CH}_{2} \mathrm{CH}_{2} \mathrm{OH}_{3}$ & 2,3 & Infinito \\
$n$-Hexanol & $\mathrm{CH}_{3} \mathrm{CH}_{2} \mathrm{CH}_{2} \mathrm{CH}_{2} \mathrm{CH}_{2} \mathrm{CH}_{2} \mathrm{OH}$ & 0,6 & Infinito \\
$n$-Heptanol $\mathrm{CH}_{3} \mathrm{CH}_{2} \mathrm{CH}_{2} \mathrm{CH}_{2} \mathrm{CH}_{2} \mathrm{CH}_{2} \mathrm{CH}_{2} \mathrm{OH}$ & 0,2 & Infinito \\
\hline
\end{tabular}

* em g de álcool / $100 \mathrm{~g}$ de solvente a $20{ }^{\circ} \mathrm{C}$; Infinito indica que a substância é completamente miscível no solvente.

A solubilidade de álcoois em água diminui com o aumento da cadeia carbônica. Quando a cadeia carbônica (hidrofóbica) aumenta, ela se torna a parte mais significativa da molécula e a substância química se torna cada vez menos solúvel, ou seja, tende a se comportar, cada vez mais, como um hidrocarboneto. Nesse caso, a formação de ligações de hidrogênio álcool-água não consegue compensar as ligações de hidrogênio água-água, que precisam ser rompidas para que ocorra o processo de dissolução (Figura 8). Por outro lado, a solubilidade dos

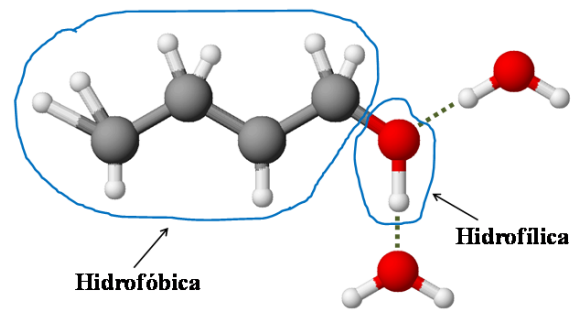

Figura 8. Ligação de hidrogênio entre butanol e água

álcoois em hexano apresenta comportamento distinto: exceto metanol, os demais álcoois referidos são totalmente miscíveis.

A solubilidade dos álcoois depende também do arranjo espacial da molécula. Por exemplo, a posição do grupo -OH em álcoois (primário, secundário ou terciário) pode levar a diferenças nas forças intermoleculares e, portanto, interferir nas propriedades físicas (Tabela 3). Assim, o álcool n-butílico, $\mathrm{CH}_{3}\left(\mathrm{CH}_{2}\right)_{2} \mathrm{CH}_{2} \mathrm{OH}$, apresenta temperatura de ebulição igual a $118^{\circ} \mathrm{C}$ e solubilidade de $7,9 \mathrm{~g} / 100 \mathrm{~g}$ de $\mathrm{H}_{2} \mathrm{O}$, enquanto os isômeros, álcool $s$-butílico, e t-butílico apresentam temperaturas de ebulição mais baixas (respectivamente $99,5^{\circ} \mathrm{C}$ e $83,0^{\circ} \mathrm{C}$ ) e solubilidades mais altas (respectivamente $12,5 \mathrm{~g} / 100 \mathrm{~g}$ de $\mathrm{H}_{2} \mathrm{O}$ e completamente miscível). ${ }^{16}$

Os fenóis tem o grupo $\mathrm{OH}$ ligado a um átomo de carbono de um anel aromático e apresentam propriedades distintas dos álcoois. Da mesma forma que os álcoois, os fenóis formam ligação de hidrogênio com a água. Contudo, devido ao número elevado de átomos de carbono, os fenóis têm solubilidade limitada em água, mas maior do que a solubilidade de álcoois alifáticos de tamanho/massa molecular similar. Por exemplo, o fenol tem a solubilidade de 8,0 g/100 g de $\mathrm{H}_{2} \mathrm{O}$ enquanto o hexanol tem a solubilidade de $0,6 \mathrm{~g} / 100 \mathrm{~g}$ de $\mathrm{H}_{2} \mathrm{O}$ (Figura 9). ${ }^{5} \mathrm{~A}$ explicação para esse fato está relacionada com a maior acidez dos fenóis $\left(\mathrm{p} K_{\mathrm{a}} \sim 10\right)$ quando comparada com a acidez dos álcoois $\left(\mathrm{p} K_{\mathrm{a}} \sim 16\right)$.

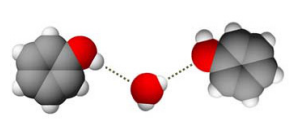<smiles>Oc1ccccc1</smiles><smiles>CCCCCCO</smiles>

(Sol. $\mathrm{H}_{2} \mathrm{O}: 8,0 \mathrm{~g} / 100 \mathrm{~g}$ )

Figura 9. Representação da ligação de hidrogênio entre água e fenol e solubilidades de fenol e hexanol em água

Em alguns fenóis orto-substituídos (como por exemplo, com o grupo nitro) é possível ocorrer a formação de ligação de hidrogênio intramolecular. A presença desta ligação dificulta o processo de solubilização em água uma vez que reduz a possibilidade de formação de ligação de hidrogênio intermolecular do tipo água-fenol. Por outro lado, a ligação de hidrogênio intramolecular contribui para o aumento da volatilidade do isômero orto que, assim, apresenta temperatura de ebulição mais baixa que o isômero para (Figura 10). ${ }^{5}$
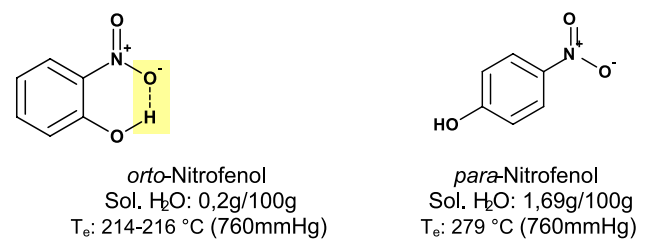

Figura 10. Representação da ligação de hidrogênio intramolecular em fenóis

\section{Éteres, aldeídos e cetonas}

Os éteres (R-O-R), os aldeídos (R-CO-H) e as cetonas (R-CO-R) constituem compostos nos quais não há possibilidade da formação das ligações de hidrogênio, quando puros. No entanto, essas interações intermoleculares são formadas quando um composto é adicionado a um solvente como a água. Devido à formação das ligações de hidrogênio durante o processo de dissolução, as solubilidades dessas classes de compostos são comparáveis às solubilidades dos álcoois: compostos com massas moleculares baixas podem ser completamente miscíveis em água, sendo bastante solúveis aqueles com até 4 átomos de carbono (Tabela 4). De maneira similar aos demais compostos, a solubilidade também diminui com o aumento da cadeia carbônica. 
Tabela 4. Solubilidade de algumas espécies em água ${ }^{5}$

\begin{tabular}{ccccc}
\hline Função & Substância & Estrutrura & $\mathrm{N}^{\circ}$ de átomos de $\mathrm{C}$ & Solubilidade $\left(\mathrm{g} / 100 \mathrm{~mL} \mathrm{H} \mathrm{H}_{2} \mathrm{O}\right)$ \\
\hline Álcool & Butanol & $\mathrm{CH}_{3} \mathrm{CH}_{2} \mathrm{CH}_{2} \mathrm{CH}_{2} \mathrm{OH}$ & 4 & $8,0\left(20^{\circ} \mathrm{C}\right)$ \\
Éter & Éter etílico & $\mathrm{CH}_{3} \mathrm{CH}_{2} \mathrm{OCH}_{2} \mathrm{CH}_{3}$ & 4 & $6,9\left(20^{\circ} \mathrm{C}\right)$ \\
Aldeído & Butanal & $\mathrm{CH}_{3} \mathrm{CH}_{2} \mathrm{CH}_{2} \mathrm{CHO}$ & 4 & $7,1\left(25^{\circ} \mathrm{C}\right)$ \\
Cetona & Butanona & $\mathrm{CH}_{3} \mathrm{COCH}_{2} \mathrm{CH}_{3}$ & 4 & $29,0\left(20^{\circ} \mathrm{C}\right)$ \\
\hline
\end{tabular}

O éter dietílico e o éter cíclico tetraidrofurano (Figura 11) são usados comumente como solventes em reações orgânicas. As cetonas também são muito utilizadas como solventes, sendo a propanona $\mathrm{CH}_{3} \mathrm{COCH}_{3}$, também chamada acetona, a mais utilizada. A propanona é uma espécie completamente miscível em água e dissolve uma grande variedade de compostos orgâncos.

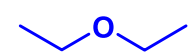

Éter dietílico

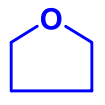

THF

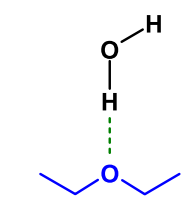

Ligação de $\mathrm{H}$ éter-água
Figura 11. Estruturas de éteres e representação da ligação de hidrogênio

\section{Ácidos carboxílicos}

Os ácidos carboxílicos, de fórmula $\mathrm{R}-\mathrm{CO}_{2} \mathrm{H}$, também contendo grupo carbonila, são altamente associados no estado líquido, uma vez que, nesse caso, as ligações de hidrogênio se formam no composto puro. Devido à formação das ligações de hidrogênio também quando misturados à água, as solubilidades dos ácidos de cadeia curta em água são altas. Ácidos com até quatro átomos de carbono são miscíveis com a água em qualquer proporção, ${ }^{17}$ enquanto que, para os ácidos de cadeia maior, a solubilidade decresce devido ao fato da cadeia carbônica se tornar a parte mais significativa da molécula. Assim, o ácido pentanóico $\mathrm{CH}_{3}\left(\mathrm{CH}_{2}\right)_{3} \mathrm{CO}_{2} \mathrm{H}$ apresenta uma solubilidade de $1 \mathrm{~g} / 30 \mathrm{~g}$ de $\mathrm{H}_{2} \mathrm{O}$, enquanto o ácido decanóico $\mathrm{CH}_{3}\left(\mathrm{CH}_{2}\right)_{8} \mathrm{CO}_{2} \mathrm{H}$ apresenta uma solubilidade de apenas $0,015 \mathrm{~g} / 100 \mathrm{~g}$ de $\mathrm{H}_{2} \mathrm{O} .^{18,19}$

É interessante observar que os ácidos carboxílicos são também relativamente solúveis em solventes imiscíveis em água, como clorofórmio, porque se dissolvem como dímeros (Figura 12).

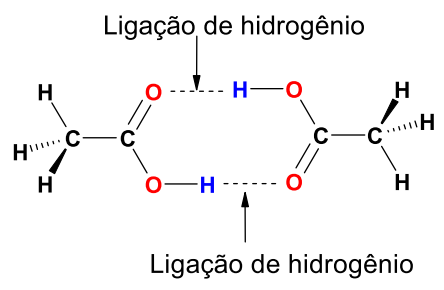

Figura 12. Representação da estrutura do dímero do ácido etanóico

A maioria dos ácidos carboxílicos não substituidos tem valores de $K_{\mathrm{a}}$ na faixa de $10^{-4}$ a $10^{-5}\left(\mathrm{p} K_{\mathrm{a}}=4\right.$ a 5$)$ e são ácidos moderadamente fortes. ${ }^{19,20}$ Devido a essa propriedade ácida, a solubilidade dessa classe de compostos pode ser fortemente modificada ao reagir com uma base. Por exemplo, o ácido benzóico, um ácido carboxílico pouco solúvel em água, ao reagir com bicarbonato de sódio é transformado em um carboxilato (uma espécie iônica) que é muito solúvel em água (Figura 13a). Os fenóis insolúveis em água dissolvem-se em solução aquosa de hidróxido de sódio, mas (exceto alguns nitrofenóis) não se dissolvem em solução aquosa de bicarbonato de sódio devido a sua menor acidez $\left(\mathrm{p} K_{\mathrm{a}} \sim 10\right)$ quando comparada com os ácidos carboxílicos (Figura 13b). Já os álcoois insolúveis em água, por serem menos ácidos ( $\left.K_{\mathrm{a}} \sim 16\right)$, não se dissolvem em solução aquosa de bicarbonato de sódio nem de hidróxido de sódio. ${ }^{19,20}$

a)

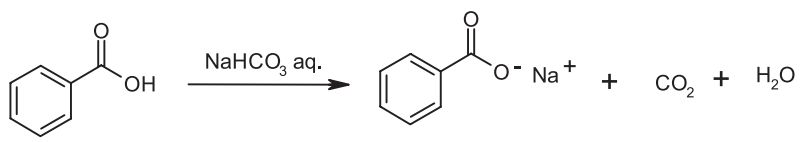

b)

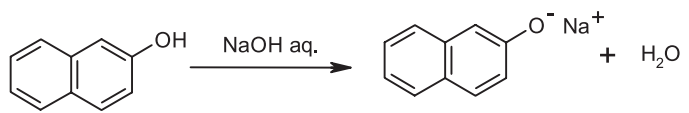

Figura 13. Formação de sal solúvel em água

\section{Ésteres}

Os ésteres, de fórmula geral R-CO-OR, também apresentam o grupo carbonila, sendo que os ésteres formiato de metila $\left(\mathrm{HCO}_{2} \mathrm{CH}_{3}\right)$ e formiato de etila $\left(\mathrm{HCO}_{2} \mathrm{CH}_{2} \mathrm{CH}_{3}\right)$ são solúveis em água, resultado da ligação intermolecular entre o hidrogênio da água e o oxigênio carbonílico. ${ }^{17}$ De maneira semelhante aos demais compostos, a solubilidade diminui à medida que a massa molecular aumenta.

As gorduras animais e óleos vegetais são constituidas de estéres de ácidos carboxílicos com cadeias carbônicas longas e o álcool 1,2,3-propanotriol, também chamado de glicerol. Na Figura 14 está representada a molécula do éster (triacilglicerol) formado a partir de ácido esteárico e glicerol. As gorduras e óleos, sendo compostos com cadeias carbônicas longas e, por isso de natureza apolar, são insolúveis em água e solúveis em solventes apolares.

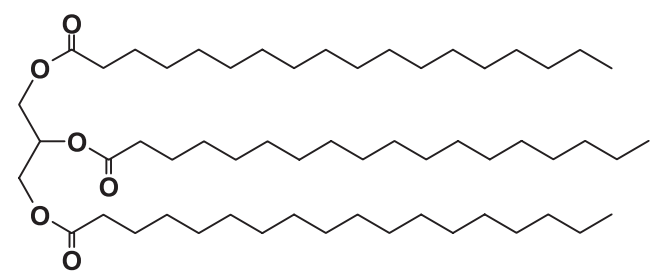

Figura 14. Molécula do éster do ácido esteárico e glicerol

A hidrólise de um triacilglicerol em presença de uma base é chamada comumente de reação de saponificação, pois um dos produtos é um sabão (que é sal de ácido graxo). Os sabões mais comuns são sais de sódio ou potássio, como por exemplo o estearato de sódio (Figura 15).

A extremidade carboxílica do sabão é altamente hidrofílica e por isso tende a interagir com a água enquanto a cadeia carbônica longa (hidrofóbica) tende a interagir com substâncias de natureza apolar. Essa estrutura permite a estabilização de gotas de óleo em água, que normalmente se separariam formando uma camada oleosa na superfície (Figura 16).

\section{Aminas}

As aminas podem ser consideradas como derivadas da amônia, 


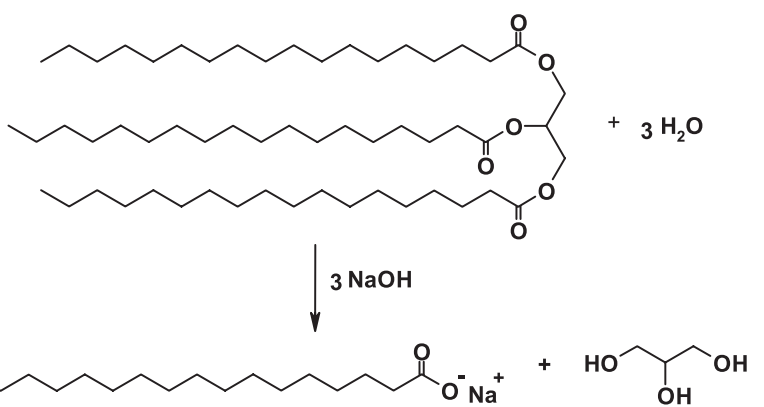

Figura 15. Reação de saponificação

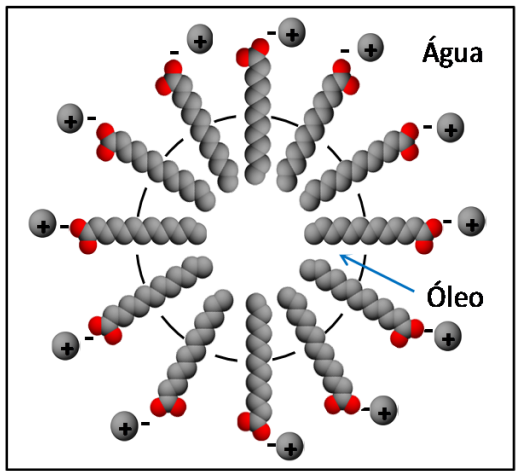

Figura 16. Representação do processo de estabilização óleo - água

$\mathrm{NH}_{3}$, pela substituição de um ou mais átomos de hidrogênio por grupos alquila, originando aminas primárias, secundárias e terciárias. Como o átomo de nitrogênio é menos eletronegativo que o oxigênio, as ligações de hidrogênio nas aminas primárias e secundárias são mais fracas do que nos álcoois de massa molecular comparável e, portanto, a tendência é apresentarem pontos de ebulição mais baixos do que esses. No entanto, aminas de todos os tipos podem se ligar à água por ligação de hidrogênio. As aminas de massa molecular menor são, portanto, espécies altamente solúveis em água. Por exemplo, a etilamina $\mathrm{CH}_{3} \mathrm{CH}_{2} \mathrm{NH}_{2}$ é completamente miscível em água e a trietilamina $\left(\mathrm{CH}_{3} \mathrm{CH}_{2}\right)_{3} \mathrm{~N}$ tem uma solubilidade igual a $13,3 \mathrm{~g} / 100 \mathrm{~mL}$ de $\mathrm{H}_{2} \mathrm{O}$ a $20{ }^{\circ} \mathrm{C} .{ }^{5}$

Aminas da alta massa molecular são geralmente insolúveis em água. Contudo, devido ao seu caráter básico, podem ser convertidas em sais solúveis em água pela reação com ácidos (Figura 17). Esta propriedade é muito importante na concepção de fármacos pois a solubilidade em água é um fator primordial na absorção, distribuição no organismo e excreção urinária.<smiles>O=[N+]([O-])c1ccc([NH2+]Cl)cc1</smiles>

Figura 17. Formação de sal solúvel em água

\section{Outros compostos}

Nos processos de solubilização de solutos polares em água, a ligação de hidrogênio entre soluto e solvente é um fator determinante na solubilidade e a regra geral "o semelhante dissolve o semelhante" deve ser usada com cuidado. Assim, o etanol $\left(\mathrm{C}_{2} \mathrm{H}_{5} \mathrm{OH}\right)$ mistura-se com água em todas as proporções enquanto o cloreto de etila $\left(\mathrm{C}_{2} \mathrm{H}_{5} \mathrm{Cl}\right)$, que possui quase o mesmo momento dipolar, é praticamente insolúvel em água. ${ }^{17}$ Dessa forma, a maior parte dos haloalcanos tendem a ser pouco solúveis em água e mais solúveis em solventes de baixa polaridade.
Por outro lado, um maior número de grupos $\mathrm{OH}$ em uma cadeia carbônica implica no incremento das ligações de hidrogênio entre o soluto e a água, aumentando a solubilidade. Assim, a alta solubilidade da sacarose e de outros açúcares em água é resultado do maior número de ligações de hidrogênio do tipo soluto-solvente. Na Figura 18 pode ser observada a representação de unidades moleculares da glicose e da frutose, cada uma contendo cinco grupos $\mathrm{OH}$, o que faz com que as moléculas apresentem alta solubilidade em água (glicose: $83 \mathrm{~g} / 100$ $\mathrm{mL}$ de $\mathrm{H}_{2} \mathrm{O}$ a $\left.17,5^{\circ} \mathrm{C}\right) .{ }^{13}$
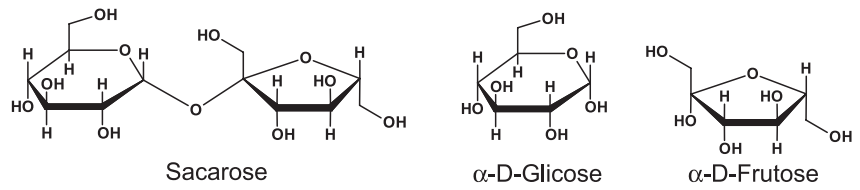

Figura 18. Estruturas da sacarose, glicose e frutose

Um cristal de açúcar (sacarose) contém muitas moléculas que são mantidas unidas pelas ligações de hidrogênio. Em água, as moléculas de sacarose estabelecem novas ligações de hidrogênio (soluto - solvente) desfazendo as ligações com as outras moléculas de sacarose (Figura 19). O resultado é a dissolução da sacarose em água, formando uma solução. A solubilidade só é possível devido às ligações de hidrogênio formadas entre o soluto (sacarose) e o solvente (água).

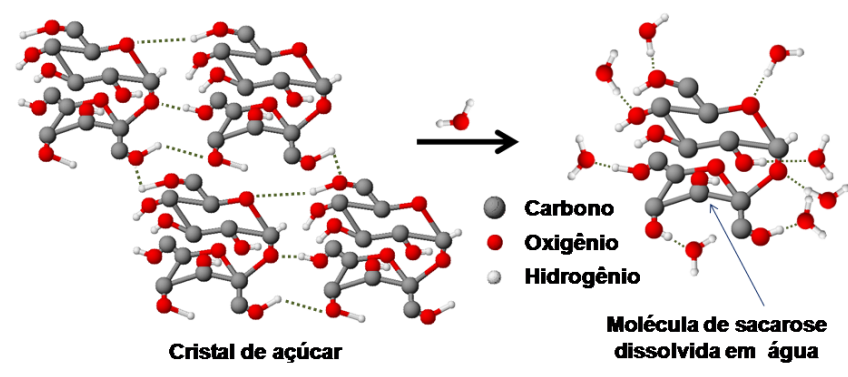

Figura 19. Representação simplificada da dissolução de sacarose em água

\section{SOLUBILIDADE E PROCESSOS BIOLÓGICOS}

As diversas funções orgânicas originam um vasto conjunto de moléculas complexas, as quais estão presentes nos organismos vivos. Para que a vida se mantenha, tais moléculas participam de diversos processos, muitas vezes governados pelas solubilidades das espécies envolvidas. A seguir são citados alguns exemplos de processos químicos diretamente relacionados à solubilidade de substâncias em líquidos biológicos.

O colesterol é uma biomolécula muito importante e pode, funcionalmente, ser classificada como um álcool (Figura 20). Por tratar-se de uma molécula relativamente grande, com apenas um grupo $\mathrm{OH}$, o colesterol, ao contrário de compostos como o metanol e o etanol, é apenas pouco solúvel em água $(0,26 \mathrm{~g} / 100 \mathrm{~mL}),{ }^{13}$ podendo depositar nas paredes de veias e artérias, contribuindo para problemas cardiovasculares nos seres vivos. Por outro lado, o colesterol é uma substância imprescindível à vida, sendo um importante constituinte
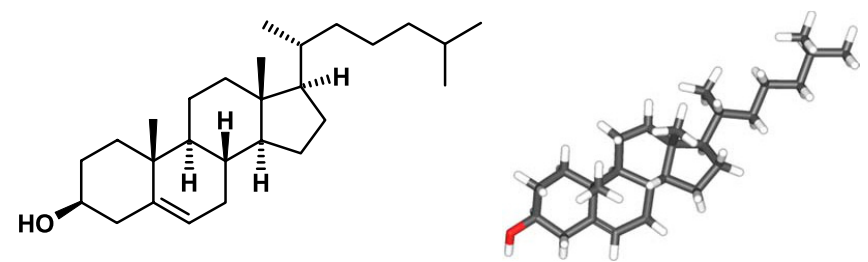

Figura 20. Diferentes representações da estrutura do colesterol 
das paredes celulares e precursor de hormônios esteróides.

A solubilidade das vitaminas em diferentes partes do corpo humano está diretamente relacionada com suas respectivas estruturas químicas. As vitaminas B e C são solúveis em água (hidrosolúveis) e as vitaminas A, D, E e K são solúveis nos tecidos adiposos (liposolúveis). Por serem solúveis em água, as vitaminas $\mathrm{B}$ e $\mathrm{C}$ não são armazenadas no organismo e, portanto, devem ser ingeridas diariamente. Ao contrário, as vitaminas liposolúveis (A, D, E e K) são armazenadas nos tecidos, permanecendo no organismo mesmo após um longo período sem a ingestão das mesmas. As diferenças nas solubilidades podem ser explicadas pelas estruturas moleculares e pelo número de grupos $\mathrm{OH}$. A vitamina $\mathrm{A}$ (retinol) é um álcool com uma cadeia carbônica longa, massa molar $=286,45 \mathrm{~g} / \mathrm{mol}$ e somente um grupo $\mathrm{OH}$. Como o grupo $\mathrm{OH}$ constitui uma parte muito pequena da molécula, o retinol pode ser considerado como uma substância pouco polar. Já a vitamina $\mathrm{C}$ pode ser considerada com uma substância polar, pois possui uma estrutura menor e um maior número de grupos $\mathrm{OH}$. Esses e os outros átomos de oxigênio na molécula podem interagir com as moléculas da água, através das ligações de hidrogênio, contribuindo para aumentar a solubilidade (Figura 21). ${ }^{13}$<smiles>CC1=C(/C=C/C(C)=C/C=C/C(C)=C/CO)C(C)(C)CCC1</smiles>

Vitamina A (Retinol) Insolúvel em água

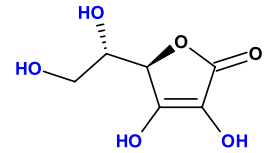

Vitamina C (Ácido ascórbico)

Solúvel em água
Figura 21. Representação das estruturas da vitamina A e da vitamina $C$

Para que as vitaminas lipossolúveis sejam absorvidas durante o processo de digestão, a vesícula biliar produz substâncias que têm estrutura química semelhante ao estearato de sódio, ou seja, uma extremidade polar (hidrofílica) e outra extremidade apolar (hidrofóbica). Essas espécies interagem com as gorduras presentes no intestino, formando uma emulsão, e permitindo a digestão e a absorção das vitaminas lipossolúveis.

Muitas substâncias apolares e insolúveis ou pouco solúveis em água, quando absorvidos pelo organismo geralmente são transformadas (metabolizadas) em compostos mais polares visando a excreção renal. $\mathrm{O}$ benzeno, um composto reconhecidamente carcinogênico e que causa efeitos prejudiciais à saúde humana, é uma substância onipresente na atmosfera devido às contribuições de emissões biogênicas e, principalmente, antrópicas. O metabolismo do benzeno, um composto lipossolúvel, ocorre principalmente no fígado. $\mathrm{O}$ benzeno (apolar) é transformado em benzeno epóxido e a partir deste intermediário são formados diversos compostos hidrossolúveis, principalmente o fenol (mais polar), que são excretados pela urina ${ }^{21}$ (Figura 22).

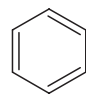

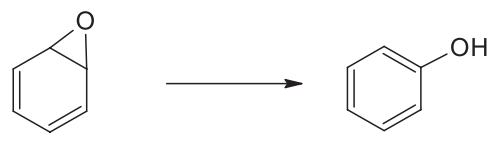

Figura 22. Representação simplificada do metabolismo do benzeno

Em outro exemplo, a eliminação do Benzo[a]pireno (BaP) pelo corpo humano envolve formação de epóxidos e, posteriormente, de compostos poliidroxilados (mais solúveis em água) que são mais facilmente eliminados pela via urinária (Figura 23). O BaP e outros hidrocarbonetos policíclicos aromáticos (HPA) estão presentes na atmosfera principalmente de grandes cidades, são formados em processo de combustão incompleta da matéria orgânica (emissões veiculares e outros processos) e apresentam potencial atividade mutagênica e cancerígena. ${ }^{21,22}$

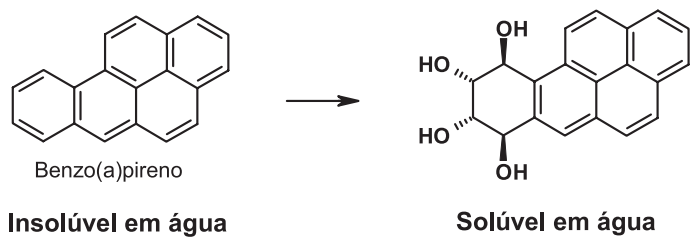

Figura 23. Representação simplificada do metabolismo do BaP

A anemia falciforme, uma doença genética, é caracterizada pela malformação das hemácias, que assumem forma semelhante a foices (de onde vem o nome da doença). A deformação das hemácias é causada por moléculas de hemoglobina presentes no sangue que apresentam uma variação em suas estruturas. As moléculas de hemoglobina normais apresentam em sua constituição um aminoácido, cuja cadeia lateral termina com um grupo polar (hidrofílico), permitindo a sua estabilização no meio aquoso na forma coloidal. Nas moléculas de hemoglobina de portadores deste tipo de anemia, a cadeia lateral é apolar (hidrofóbica), o que faz com que essas moléculas defeituosas se agreguem, formando estruturas maiores que cristalizam no interior das hemácias, provocando a distorção das células que passam a ter a forma de foice (Figura 24). ${ }^{13}$<smiles>[R]CC(=O)O</smiles>

Glóbulos vermelhos normais (com grupo polar)<smiles>[R]CC(C)C</smiles>

Glóbulos vermelhos falciformes (com grupo apolar)
Figura 24. Representação de parte da estrutura de moléculas de hemoglobina

\section{CONCLUSÕES}

A solubilidade das espécies orgânicas em solventes polares ou apolares, de uma maneira geral, está relacionada com a polaridade do soluto e do solvente em questão. Solutos apolares em solventes também apolares formam as soluções chamadas ideais, uma vez que todas as interações envolvidas no processo são interações fracas e possuem a mesma ordem de grandeza (forças de London).

A análise dos coeficientes de solubilidade de solutos polares em solventes também polares, levando em conta o valor do momento de dipolo das espécies, deve ser feita com cautela. Compostos apresentando valores iguais para o momento de dipolo podem exibir solubilidades bem distintas em solventes como a água, em função da possibilidade ou não, da formação de ligações de hidrogênio entre o soluto e o solvente, o que afeta fortemente a solubilidade.

Muitos processos biológicos podem estar diretamente relacionados com a solubilidade das substâncias orgânicas, uma vez que essas podem ser apolares ou fracamente polares e portanto liposolúveis, ou se apresentar polares - com possibilidade de formação das ligações de hidrogênio - o que as tornam altamente solúveis na fase aquosa.

\section{AGRADECIMENTOS}

Os autores agradecem aos professores S. do D. Cunha e P. A. de P. Pereira pelas valiosas sugestões, à FAPESB e CNPq (INCT de Energia e Ambiente) pelo apoio financeiro.

\section{REFERÊNCIAS}

1. Silva, L. A.; Martins, C. R.; de Andrade, J. B.; Quim. Nova 2004, 27, 1016 
2. Martins, C. R.; Silva, L. A.; de Andrade, J. B.; Quim. Nova 2010, 33, 2283.

3. Haynes, W. M. (Editor). CRC Handbook of Chemistry and Physics, $91^{\mathrm{st}}$ ed., CRC Press: Cleveland, 2010-2011.

4. Perry, R. H.; Chilton, C. H.; Chemical Engineers' Handbook, $7^{\text {th }}$ ed., McGraw-Hill: EUA, 1997.

5. http://www.chemicalbook.com/, acessada em Junho 2013.

6. http://srdata.nist.gov/solubility/, acessada em Junho 2013.

7. Katritzky, A. R.; Kuanar, M.; Slavov, S.; Hall, C. D.; Chem. Rev. 2010, 110, 5714

8. Huheey, J. E.; Kelter, E. A.; Kelter, R. L.; Inorganic Chemistry: Principles of Struture and Reactivity, $4^{\text {th }}$ ed., Harper Collins College Publishers: New York, 1993.

9. Costa Neto, C.; Análise Orgânica: Métodos e Procedimentos para a Caracterização de Organoquímios, Editora UFRJ: Rio de Janeiro, 2004.

10. Pavia, D. L.; Lampman, G. M.; Kriz, G. S.; Engel. R. G.; Química Orgânica Experimental, $3^{a}$ ed., Cengage Learning: São Paulo, 2012.

11. Vogel, A. I.; Química Orgânica: análise orgânica qualitativa, $1^{\mathrm{a}} \mathrm{ed}$., Ao Livro Técnico: Rio de Janeiro, 1983.

12. Shriner, R. L.; Fuson, R. C.; Curtin, D. Y.; Morrill, T. C.; Identificação Sistemática dos Compostos Orgânicos, $6^{\mathrm{a}}$ ed., Guanabara Dois: Rio de Janeiro, 1983.
13. Bronw, L. S.; LeMay, H. E..; Bursten, B. E.; Química A Ciência Central, $9^{a}$ ed., Pearson Education do Brasil: São Paulo, 2007.

14. McMurry, J.; Química Orgânica, $7^{\mathrm{a}}$ ed., Cengage Learning: São Paulo, 2011.

15. Gierszal, K. P.; Davis, J. G.; Hands, M. D.; Wilcox, D. S.; Slipchenko, L. V.; Ben-Amotaz, D.; J. Phys. Chem. Lett. 2011, 2, 2940.

16. Morrison, R.; Boyd, R.; Química Orgânica, 13ª ed., Fundação Calouste Gulbenkian: Lisboa, 1996.

17. Russel, J. B.; Química Geral, 2a ed., Makron Books: São Paulo, 1994.

18. Constantino, M. G.; Química Orgânica - Curso Básico Universitário, LTC: Rio de Janeiro, 2012

19. Bruice, P. Y.; Química Orgânica, 4ª ed., Prentice Hall: São Paulo, 2006.

20. Solomons, T. W. G.; Fryhle, C. B.; Química Orgânica, 10ª ed., LTC: Rio de Janeiro, 2012.

21. Coutrim, M. X.; de Carvalho, L. R. F.; Arcuri, A. S. A.; Quim. Nova 2000, 23, 653 .

22. Lopes, W. A.; de Andrade, J. B; Quim. Nova 1996, 19, 497. 